\title{
Development and content of the biopsychosocial primary care intervention 'Back on Track' for a subgroup of people with chronic low back pain
}

Citation for published version (APA):

van Erp, R. M. A., Huijnen, I. P. J., Koke, A. J. A., Abbin, F. E., den Hollander, M., \& Smeets, R. J. E. M. (2017). Development and content of the biopsychosocial primary care intervention 'Back on Track' for a subgroup of people with chronic low back pain. Physiotherapy, 103(2), 160-166. https://doi.org/10.1016/j.physio.2016.04.004

Document status and date:

Published: 01/06/2017

DOI:

10.1016/j.physio.2016.04.004

Document Version:

Publisher's PDF, also known as Version of record

Document license:

Taverne

Please check the document version of this publication:

- A submitted manuscript is the version of the article upon submission and before peer-review. There can be important differences between the submitted version and the official published version of record.

People interested in the research are advised to contact the author for the final version of the publication, or visit the DOI to the publisher's website.

- The final author version and the galley proof are versions of the publication after peer review.

- The final published version features the final layout of the paper including the volume, issue and page numbers.

Link to publication

\footnotetext{
General rights rights.

- You may freely distribute the URL identifying the publication in the public portal. please follow below link for the End User Agreement:

www.umlib.nl/taverne-license

Take down policy

If you believe that this document breaches copyright please contact us at:

repository@maastrichtuniversity.nl

providing details and we will investigate your claim.
}

Copyright and moral rights for the publications made accessible in the public portal are retained by the authors and/or other copyright owners and it is a condition of accessing publications that users recognise and abide by the legal requirements associated with these

- Users may download and print one copy of any publication from the public portal for the purpose of private study or research.

- You may not further distribute the material or use it for any profit-making activity or commercial gain

If the publication is distributed under the terms of Article $25 \mathrm{fa}$ of the Dutch Copyright Act, indicated by the "Taverne" license above, 
Debate Article

\title{
Development and content of the biopsychosocial primary care intervention 'Back on Track' for a subgroup of people with chronic low back pain
}

\author{
R.M.A. van $\operatorname{Erp}^{\text {a,* }}$, I.P.J. Huijnen ${ }^{\text {a,b,c }}$, A.J.A. Köke ${ }^{\text {a,c,d }}$, F.E. Abbink ${ }^{\text {d,e }}$, \\ M. den Hollander ${ }^{\text {b,f }}$, R.J.E.M. Smeets ${ }^{\mathrm{a}, \mathrm{g}}$ \\ a Department of Rehabilitation Medicine, Research School of CAPHRI, Maastricht University, Maastricht, The Netherlands \\ ${ }^{\mathrm{b}}$ Department of Rehabilitation Medicine, Maastricht UMC+, Maastricht, The Netherlands \\ ${ }^{\mathrm{c}}$ Adelante, Centre of Expertise in Rehabilitation and Audiology, Hoensbroek, The Netherlands \\ ${ }^{\mathrm{d}}$ Faculty of Health, Department of Physiotherapy, Zuyd University of Applied Sciences, Heerlen, The Netherlands \\ ${ }^{\mathrm{e}}$ Fysiotherapie Abbink, Ulestraten, The Netherlands \\ ${ }^{\mathrm{f}}$ Department of Clinical Psychological Science, Maastricht University, Maastricht, The Netherlands \\ ${ }^{\mathrm{g}}$ Libra Rehabilitation and Audiologie location Blixembosch, Eindhoven and location Weert, and Sint Jans Gasthuis, Weert, \\ The Netherlands
}

\begin{abstract}
Biopsychosocial interventions provided in multidisciplinary settings are promising for improving functional disability levels in patients with chronic low back pain (CLBP). These multidisciplinary biopsychosocial interventions mainly focus on cognitive-behavioural approaches that aim to change negative cognitions, emotions, behaviour, work and social factors. As some patients with CLBP treated in primary care settings also experience psychosocial factors that influence their level of disability, these patients may benefit from the provision of a biopsychosocial intervention in primary care. This paper will provide a detailed description of the development and content of the biopsychosocial primary care intervention 'Back on Track' for this specific subgroup of patients. The Back on Track intervention was developed based on available scientific evidence and clinical experience from multidisciplinary pain rehabilitation programmes, and its effectiveness is currently being tested.

Clinical Trial Registration Number NCT02220543.
\end{abstract}

(C) 2016 Chartered Society of Physiotherapy. Published by Elsevier Ltd. All rights reserved.

Keywords: Low back pain; Chronic pain; Cognitive behavioural therapy; Primary health care; Physical therapy

\section{Introduction}

Developing effective interventions for patients with nonspecific chronic low back pain (CLBP) is challenging. Despite the fact that CLBP is very common, affecting approximately $21 \%$ of the general adult population (age $>18$ years) [1], there is still ongoing debate about the most

\footnotetext{
* Corresponding author. Address: Department of Rehabilitation Medicine, CAPHRI, Maastricht University, Universiteitssingel 40, P.O. Box 616, 6200 MD Maastricht, The Netherlands. Tel.: +31 433882168.

E-mail address: reni.vanerp@ maastrichtuniversity.nl (R.M.A. van Erp).
}

appropriate treatment strategy. As no medical cure for pain exists, many treatments, based on a biopsychosocial model, focus on teaching patients how to cope with their pain and pain-related disability. Examples are exercise therapy, back schools, psychological or behavioural treatment, and multidisciplinary rehabilitation [2]. At present, national and international guidelines recommend (multidisciplinary) biopsychosocial interventions for the management of CLBP [3-5]. Also, systematic reviews analysing randomised controlled trials (RCTs) found more promising results for multidisciplinary biopsychosocial interventions than other treatments or waiting lists for the improvement of disability levels $[2,6]$. 
Biopsychosocial interventions combine different treatment modalities to target physical, psychological and social factors based on the assumption that (a combination of) psychological and social factors are related to the persistence of chronic pain and the associated level of disability $[7,8]$. Wellknown psychological factors are negative or catastrophising thoughts that some patients develop after injury or due to the experience of persistent pain. For example, patients think or expect that certain activities or movements will cause (re)injury. Due to these negative thoughts, patients develop pain-related fear (i.e. being afraid to harm themselves or experience pain when performing functional activities). This leads to fear-avoidance behaviour, resulting in higher levels of inactivity and functional disability. Other patients may not avoid activities completely but act 'pain contingently', and stop performing activities once they experience pain. Over time, this can lead to higher functional disability [7].

However, CLBP is not limited solely to the patient, but also affects the social environment. For example, a spouse might need to take more responsibility for household or parenting activities, and relationships with colleagues and friends might change due to reduced ability to perform social or workrelated activities. Overall, it is suggested that patients with less social support at home/work are more likely to develop CLBP [9]. However, where family members, friends or colleagues are supportive but have negative perceptions about (the consequences of) pain themselves, they might advise patients to avoid activities causing pain, to take medicine or to rest in bed $[10,11]$. They can unconsciously restrict a patient's performance of daily activities and reinforce passive coping styles, and by doing so, play a significant role in the patient's pain problem.

The types of psychosocial factors present and the degree to which they influence CLBP varies between patients. Heterogeneity in profile subsequently leads to heterogenic responses to interventions [12]. Therefore, identification of psychosocial factors by healthcare professionals seems to be of fundamental importance to provide the most suitable treatment $[13,14]$.

In current daily practice, patients with complex (severe) psychosocial factors reporting high levels of functional disability are the main recipients of biopsychosocial interventions in multidisciplinary pain rehabilitation settings. Patients with less complex or no psychosocial factors receive interventions in primary care settings. These interventions generally include information or advice (32\%), exercise therapy (81\%) and manual therapy (massage, manual manipulation; 76\%) [15]. Based on the assumption that primary care patients might also benefit from biopsychosocial interventions, a new biopsychosocial primary care intervention ('Back on Track') has been developed. This intervention aims specifically at identification and modification of influencing psychosocial factors. The Back on Track intervention is currently under evaluation and will be compared with primary care physiotherapy in a multicentre $(n=8)$ doubleblind RCT [16]. Usually, publications about clinical trials provide limited information about the content of the intervention. This article has therefore been compiled to give a detailed description of the biopsychosocial Back on Track intervention to facilitate healthcare providers in understanding and reproducing biopsychosocial interventions in clinical practice.

\section{Development of the Back on Track intervention}

The Back on Track intervention is a primary care physiotherapy treatment developed by Dutch physiatrists, psychologists and physiotherapists working in primary and secondary healthcare settings. Furthermore, members of the Dutch Association of Back Pain 'de Wervelkolom' were invited to provide feedback. The Back on Track intervention is based on available scientific evidence and currently applied evidence-based multidisciplinary pain rehabilitation programmes used at the Department of Rehabilitation Medicine, Maastricht UMC+ (Maastricht, The Netherlands) and Adelante, Centre of Expertise in Rehabilitation and Audiology (Hoensbroek, The Netherlands). Multidisciplinary pain rehabilitation programmes aim to improve daily activity levels by using cognitive-behavioural approaches such as graded activity (GA) and graded exposure in vivo (GE) in combination with pain education. GA and GE have been shown to be equally effective for improving functional disability in patients with CLBP $[17,18]$. Pain education as an integral part of GA and GE or on its own has also been shown to be effective [19]. The Back on Track intervention includes the abovementioned approaches but at a lower intensity, as patients in primary care often experience less severe psychosocial factors than patients referred to multidisciplinary pain rehabilitation programmes. In general, the main objectives of the Back on Track intervention are:

- to understand pain mechanisms and differences between acute and chronic pain;

- to become aware of the role of physical, cognitive and social factors;

- to become aware of the influence of pain behaviour in the short and long term;

- to reduce negative/catastrophising thoughts, pain-related fear and fear-avoidance behaviours/compensatory behaviour;

- to stimulate active coping styles by providing different self-management strategies; and

- to reduce functional disability levels.

\section{The Back on Track intervention format}

\section{Intensity and duration}

The Back on Track intervention consists of four individual and eight group sessions (Table 1). Within this format, 8 hours will be used for education/discussion and 2 hours 
Table 1

Schematic view of the Back on Track intervention.

\begin{tabular}{lll}
\hline Sessions & Content/strategy & $\begin{array}{l}\text { Duration } \\
\text { (minutes) }\end{array}$ \\
\hline Individual & History taking & 30 \\
& Pain education & 30 \\
& Goal setting & 30 \\
Group & Theme 1 - Pain and physical activity & \\
& $\quad$ Session 1 education & 60 \\
& Session 2 education + physical activity & $30+30$ \\
& Theme 2 - Pain and social network & 60 \\
& $\quad$ Session 1 education & $30+30$ \\
& Session 2 education + physical activity & 60 \\
& Theme 3 - Pain and cognitions & $30+30$ \\
& $\quad$ Session 1 education & \\
& $\quad$ Session 2 education + physical activity & 60 \\
& Theme 4 - Fact or myth? & $30+30$ \\
& Session 1 education & 30 \\
\hline Individual & Session 2 education + physical activity &
\end{tabular}

will be used for performing physical activity. From the literature, it is known that education of at least 2.5 hours is more effective than less intensive or no education [20]. In exercise therapy, no differences in effectiveness on disability levels are reported between extensive (20 to 30 sessions of 30 minutes) and shorter (six to 10 sessions of 30 minutes) interventions [21]. As no standards are available about the intensity of interventions, the dose/intensity of the Back on Track intervention is based on the available resources in primary care, competence of physiotherapists, and an amount that will presumably induce behavioral changes.

The total duration of the programme is approximately 8 weeks when provided twice per week. As more than half of primary care patients with CLBP receive at least 10 physiotherapy sessions over a treatment period of at least 6 weeks in daily practice [22], it is expected that the intervention would be feasible to implement.

\section{Individual and group sessions}

The Back on Track intervention includes both individual and group sessions. Individual sessions are included to gain detailed insight in the patient-specific situation (history, psychosocial factors, goals) and to enhance the patient-therapist relationship. Group sessions are included to stimulate discussion between patients (e.g. about influencing psychosocial factors, difficulties in life and differences in pain behaviour or coping styles). Discussing these topics can lead to mutual support and observational learning which may stimulate active coping styles (i.e. observing positive consequences of certain behaviour in other patients may inspire confidence and may lead to imitation of these coping styles) $[23,24]$. Another advantage of group therapy is the potential costeffectiveness compared with individual therapy [25]. Back on Track groups include three to five patients, and are administered by one physiotherapist. A minimum of three patients is chosen as smaller group sizes are expected to lead to less group interaction, while a maximum of five patients is chosen for practicability reasons (facilities).

\section{Method of delivery}

Who delivers the Back on Track intervention?

The Back on Track intervention is designed for primary care physiotherapists. However, it has been shown that the attitude (biomedical or biopsychosocial) of a healthcare provider influences the strategy of the actual treatment and the advice provided to patients [26]. Motivation and skills of the physiotherapist are therefore important prerequisites for sufficient treatment delivery.

\section{Treatment protocol and educational programme}

A treatment manual with detailed theoretical and practical information has been developed to standardise practical implementation. Also, an educational programme has been developed including three 4-hour meetings to ensure basic knowledge and understanding of cognitive-behavioural approaches and accurate delivery of the intervention. The length of the educational programme was derived from the 2-day programme of the study of Lamb et al., which resulted in a well-implemented and effective primary care cognitivebehavioural-based programme $[27,28]$.

\section{Information booklets}

It has been shown that providing general information about pain and the treatment rationale are effective elements of treatment [29,30]. Moreover, written information in conjunction with verbal information seems to be effective in changing pain perceptions and the health status of patients [30]. As such, an information booklet has been created for patients with basic information, helpful illustrations and home assignments.

\section{Detailed description of the Back on Track intervention}

\section{Referral procedure}

It is favourable if a patient is referred by a healthcare professional specialised in chronic pain. Skilled professionals can identify psychosocial factors and can introduce the biopsychosocial programme by providing education, including an explanation about the current health status, the meaning of chronic pain (hurt does not mean harm), and advice to perform normal daily activities despite pain. By providing education, the healthcare professional can reinforce the credibility of the biopsychosocial approach, and prepare 


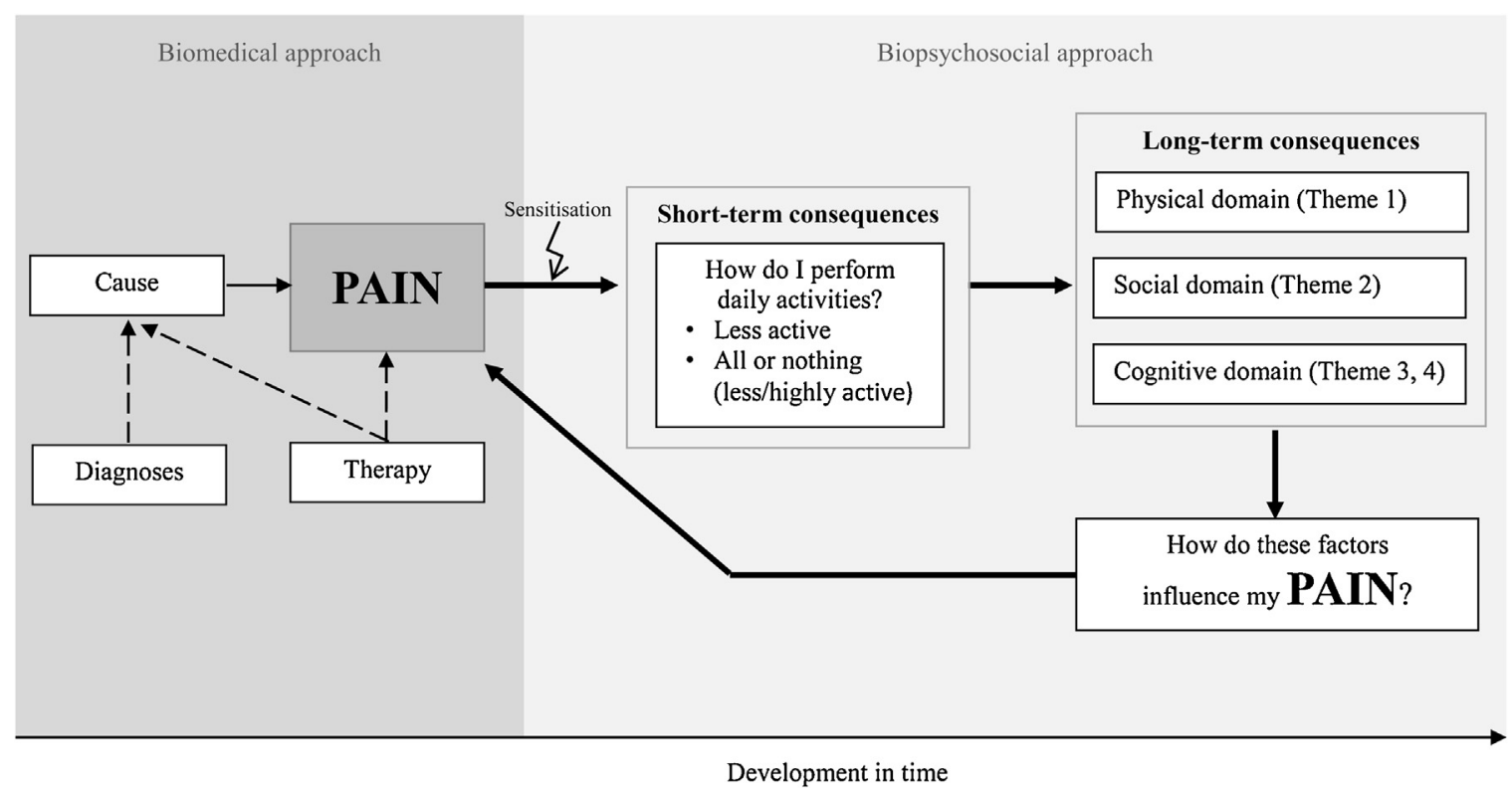

Fig. 1. The pain-consequence model. This model acts as a framework for the Back on Track intervention. The model addresses multiple relevant biomedical factors (left) and biopsychosocial factors (right) that may contribute to the development and/or persistence of chronic low back pain.

patients for a different approach than normally expected in primary care.

\section{Individual sessions}

\section{Individual session 1}

The intervention starts with a combination of history taking and pain education using the pain-consequence model; this model is used frequently in Dutch clinical practice (Fig. 1). The model consists of two parts; a biomedical part (or causal explanation of pain) and a biopsychosocial part (or consequences that contribute to chronicity). During the first session, the biomedical part is discussed to provide insight into results and successes of previously received medical diagnoses, advice and treatments. The patient must eventually start to recognise that continuing a biomedical approach is probably unproductive and, due to the complexity of the pain problem, a transition to a more biopsychosocial orientation is needed. Pain education prepares the patient for the different treatment approach (improving daily functioning despite pain and no pain reduction), and increases readiness to change coping styles. A short functional examination can also be performed to gain insight into pain behaviour during lifting, bending or dressing (e.g. avoidance or compensatory).

\section{Individual session 2}

During the second session, the attention shifts to the biopsychosocial part of the pain-consequence model. First, pain mechanisms and the transition from acute to chronic pain are discussed in order to improve knowledge and understanding about pain. Secondly, and as insight progresses, factors that a patient recognises as contributing to his/her own pain problem are discussed. At home, the patient selects the three functional activities that are most restricted due to CLBP using the Dutch Patient Specific Functional Scale (PSFS) [31].

\section{Individual session 3}

For the three most restricted and valuable functional activities selected from the PSFS, patient-specific goals are set collaboratively according to the SMART principles (i.e. specific, measurable, achievable and realistic in a certain timeframe). Homework assignment includes performing selected activities on a pain-contingent basis to set up a baseline performance measure. This baseline will eventually be used to set up a starting point for GA (Theme 1).

\section{Group sessions}

After three individual sessions, eight group sessions are provided twice a week. Each week focuses on one of the four themes (Table 1). The first session of a week/theme includes 1 hour of education, while the second session includes a combination of education and physical activity. The following section provides information about each education session for each theme. Subsequently, all physical activity sessions are discussed together because of the overlap between these sessions.

\section{Theme 1. Pain and physical activity}

Pain can stimulate a patient to stop performing activities (acting pain contingently), which often leads to pain reduction in the short term. However, in the long term, this pain behaviour can result in reduced daily life functioning. Therefore, Theme 1 discusses patients' own pain 
behaviour and related short- and long-term consequences. The operant conditioning behavioural approach, GA [32], is introduced to encourage active coping styles. Furthermore, patients develop a GA plan based on self-measured activity levels (derived from homework assignment in the third individual session) in order to increase their performance levels gradually and time contingently. Patients are encouraged to use their GA plans during therapy (physical activity therapy sessions) and at home (homework assignment).

\section{Theme 2. Pain and social network}

Social factors, such as family (spousal/partner support), work (colleague support, job stress) and health care (physiotherapist's empathy, communication), can play an important role in the development and/or persistence of chronic pain $[9,33]$. Social factors should be recognised as external factors that can influence a patient's attitude towards pain either positively or negatively. Theme 2 therefore discusses the patient's own coping strategies in relation to coping strategies of their significant others. This might eventually stimulate lifestyle changes and pain behaviour. Homework assignment is to write down how significant others respond whenever the patient experiences pain, and how the patient subsequently reacts to that response. In this way, a patient can learn operant-conditioning mechanisms that contribute to the maintenance of pain and pain-related disability.

\section{Theme 3. Pain and cognitions}

As mentioned previously, some patients generate catastrophising thoughts after the experience of pain and develop pain-related fear and kinesiophobia. This can lead to lower levels of activity and higher functional disability [7]. It has been shown that therapy can modify catastrophising thinking, and a reduction in catastrophising thinking is related to better treatment outcomes [34,35]. Although the target group of the Back on Track intervention may not encounter extreme catastrophising thoughts, a patient may still encounter negative thoughts that can lead to different movement strategies [36]. Theme 3 therefore discusses what types of cognitions are present about daily activities. The Photograph Series of Daily Activities - Short Electronic Version is used to measure the threat value of daily activities [ranging from 0 ('not harmful at all') to 100 ('extremely harmful')] and to determine a hierarchy of the patient's fearful activities [37]. At home, patients define and rate (new) threatening functional activities (homework assignment).

\section{Theme 4. Fact or myth?}

It has been shown that misbeliefs about low back pain still exist in the general population (e.g. the need for bed rest, or the need to use radiographs or other imaging tests to identify the cause of pain) [38]. Misbeliefs may be caused due to the inability of professionals to translate information to a patient's level, poor non-scientific sources of information available in the media, or the inability of the patient to interpret information appropriately [7]. Theme 4 therefore aims to discuss (and to reach consensus) about facts and myths with regard to low back pain. Discussions about misbeliefs will improve knowledge and may indirectly stimulate active coping styles. In case uncertainties or questions are still present after this session, they must be recorded by the patient (homework) and discussed in subsequent sessions.

This session also addresses the impact of helpful (positive) or non-helpful (negative) thoughts on mood and disability level. It is important to clarify what type of thoughts, either positively or negatively tuned, the patient experiences in certain situations such as waking up, going to a birthday party, sports, work etc. At home, the patient should write down their own thoughts and feelings in different situations, and determine whether these cognitions are positively or negatively tuned.

\section{Physical activity sessions}

The four physical activity sessions are provided as a second session each week and start by repeating cognitive-behavioural principles, previous discussions and self-management strategies. Secondly, sports activities are performed. The main aim of these sessions is to become physically active, to inspire confidence and to have pleasure in being physically active. Physiotherapists observe behaviour and confront the patient with their own (unconscious) pain behaviour. Sports activities are based on the preferences of the group and the available sports facilities. The type or content of sports activities is therefore not protocolled, apart from Theme 3.

During the physical activity session of Theme 3, the patient is challenged to test their own negative cognitions using GE principles. GE exposes patients to fearful functional activities in order to experience the inconsistency of previous expectations with actual consequences of the activity. Eventually, this leads to reduced pain-related fear and improved functional activity levels [39,40].

Homework assignment for physical activity sessions is to improve functional activities by executing personal GA plans or immediate exposure.

\section{Evaluation session}

At the end of the intervention, an individual evaluation session is provided to assess the experiences of the patient, the actual status, improvements in functional disability levels and ability to generalise perceived knowledge into home situations. The physiotherapist discusses difficulties and ways to cope with situations in case back pain recurs. If the improvements, generalisability and coping behaviour of the patient are not sufficient, referral back to the referring healthcare professional is indicated. 


\section{Discussion}

This article provides a description of the biopsychosocial primary care intervention 'Back on Track'. This intervention is specifically developed for patients with CLBP who experience non-complex psychosocial factors and in whom the level of disability is low to moderate. The intervention is based on available scientific evidence and clinical experience from multidisciplinary pain rehabilitation programmes. Currently, the intervention is under evaluation in an RCT, the results of which are expected to be available in June 2017. The detailed description of the RCT design can be found elsewhere [16]. If the intervention proves to be effective, this article may facilitate other healthcare professionals to implement biopsychosocial interventions in clinical practice.

\section{Acknowledgements}

The authors wish to thank Jeanine Verbunt, Paul Willems and the Dutch Association of Back Patients 'de Wervelkolom' for their contribution to the development of the Back on Track intervention. Furthermore, the authors wish to thank the Department of Rehabilitation in Medicine MUMC+, Spine Center MUMC+ and Fy'net Collaboration for management of the trial.

Ethical approval: Institutional Medical Ethics Committee of the University Hospital of Maastricht and Maastricht University (Ref. No. METC143019).

Funding: Adelante, Centre of Expertise in Rehabilitation and Audiology Hoensbroek, The Netherlands; the Province of Limburg (SAS-2012-01300) and CZ Foundation (AFVV12205).

Conflict of interest: None declared.

\section{References}

[1] Picavet HS, Schouten JS. Musculoskeletal pain in the Netherlands: prevalences, consequences and risk groups, the DMC(3)-study. Pain 2003;102:167-78.

[2] van Middelkoop M, Rubinstein SM, Kuijpers T, Verhagen AP, Ostelo R, Koes BW, et al. A systematic review on the effectiveness of physical and rehabilitation interventions for chronic non-specific low back pain. Eur Spine J 2011;20:19-39.

[3] Royal Dutch Society for Physical Therapy (KNGF). KNGF evidence-based clinical practice guidelines. Amersfoort: KNGF; 2013. Available at: https://www.fysionet-evidencebased.nl/index. php/kngf-guidelines-in-english [accessed 12.02.16].

[4] Airaksinen O, Brox JI, Cedraschi C, Hildebrandt J, Klaber-Moffett J, Kovacs F, et al. European guidelines for the management of chronic nonspecific low back pain. Eur Spine J 2006;15(Suppl. 2):S192-300 [chapter 4].

[5] Dutch Institute for Healthcare Improvement (CBO). Clinical guideline for non-specific low back pain. Alphen aan den Rijn: CBO; 2003 [in Dutch].
[6] Kamper SJ, Apeldoorn AT, Chiarotto A, Smeets RJ, Ostelo RW, Guzman J, et al. Multidisciplinary biopsychosocial rehabilitation for chronic low back pain. Cochrane Database Syst Rev 2014;9:CD000963.

[7] Vlaeyen JW, Linton SJ. Fear-avoidance and its consequences in chronic musculoskeletal pain: a state of the art. Pain 2000;85:317-32.

[8] Waddell G. The back pain revolution. Oxford: Churchill Livingstone; 2004.

[9] Melloh M, Salathe CR, Elfering A, Kaser A, Barz T, Aghayev E, et al. Occupational, personal and psychosocial resources for preventing persistent low back pain. Int J Occup Saf Ergon 2013;19:29-40.

[10] Fordyce WE. Behavioral methods for chronic pain and illness. St. Louis, MO: Mosby; 1976.

[11] Leonard MT, Cano A, Johansen AB. Chronic pain in a couples context: a review and integration of theoretical models and empirical evidence. J Pain 2006;7:377-90.

[12] George SZ, Fritz JM, Bialosky JE, Donald DA. The effect of a fear-avoidance-based physical therapy intervention for patients with acute low back pain: results of a randomized clinical trial. Spine 2003;28:2551-60.

[13] Hill JC, Dunn KM, Lewis M, Mullis R, Main CJ, Foster NE, et al. A primary care back pain screening tool: identifying patient subgroups for initial treatment. Arthritis Rheum 2008;59:632-41.

[14] Vibe Fersum K, O'Sullivan P, Skouen JS, Smith A, Kvale A. Efficacy of classification-based cognitive functional therapy in patients with nonspecific chronic low back pain: a randomized controlled trial. Eur J Pain 2013;17:916-28.

[15] Swinkels IC, van den Ende CH, van den Bosch W, Dekker J, Wimmers RH. Physiotherapy management of low back pain: does practice match the Dutch guidelines? Aust J Physiother 2005;51:35-41.

[16] Erp RM, Huijnen IP, Verbunt JA, Smeets RJ. A biopsychosocial primary care intervention (Back on Track) versus primary care as usual in a subgroup of people with chronic low back pain: protocol for a randomised, controlled trial. J Physiother 2015;61:155.

[17] Leeuw M, Goossens ME, van Breukelen GJ, de Jong JR, Heuts PH, Smeets RJ, et al. Exposure in vivo versus operant graded activity in chronic low back pain patients: results of a randomized controlled trial. Pain 2008;138:192-207.

[18] George SZ, Wittmer VT, Fillingim RB, Robinson ME. Comparison of graded exercise and graded exposure clinical outcomes for patients with chronic low back pain. J Orthop Sports Phys Ther 2010;40:694-704.

[19] Louw A, Diener I, Butler DS, Puentedura EJ. The effect of neuroscience education on pain, disability, anxiety, and stress in chronic musculoskeletal pain. Arch Phys Med Rehabil 2011;92:2041-56.

[20] Engers A, Jellema P, Wensing M, van der Windt DA, Grol R, van Tulder MW. Individual patient education for low back pain. Cochrane Database System Rev 2008;1:CD004057.

[21] Ferreira ML, Smeets RJ, Kamper SJ, Ferreira PH, Machado LA. Can we explain heterogeneity among randomized clinical trials of exercise for chronic back pain? A meta-regression analysis of randomized controlled trials. Phys Ther 2010;90:1383-403.

[22] Engers AJ, Schers H, Oostendorp RAB. Het handelen van Nederlandse fysiotherapeuten bij lage-rugpijn: een beschrijvend onderzoek van de dagelijkse praktijk. Ned Tijdschr Fysiother 2001;6:142-51.

[23] Carnes D, Homer KE, Miles CL, Pincus T, Underwood M, Rahman A, et al. Effective delivery styles and content for self-management interventions for chronic musculoskeletal pain: a systematic literature review. Clin J Pain 2012;28:344-54.

[24] Bandura A. Social foundations of thought and action: a social cognitive theory. Englewood Cliffs, NJ: Prentice Hall; 1986.

[25] Critchley DJ, Ratcliffe J, Noonan S, Jones RH, Hurley MV. Effectiveness and cost-effectiveness of three types of physiotherapy used to reduce chronic low back pain disability: a pragmatic randomized trial with economic evaluation. Spine 2007;32:1474-81.

[26] Bishop A, Foster NE, Thomas E, Hay EM. How does the self-reported clinical management of patients with low back pain relate to the attitudes and beliefs of health care practitioners? A survey of UK general practitioners and physiotherapists. Pain 2008;135:187-95. 
[27] Lamb SE, Hansen Z, Lall R, Castelnuovo E, Withers EJ, Nichols V, et al. Group cognitive behavioural treatment for low-back pain in primary care: a randomised controlled trial and cost-effectiveness analysis. Lancet 2010;375:916-23.

[28] Lamb SE, Mistry D, Lall R, Hansen Z, Evans D, Withers EJ, et al. Group cognitive behavioural interventions for low back pain in primary care: extended follow-up of the Back Skills Training Trial (ISRCTN54717854). Pain 2012;153:494-501.

[29] Del Bano-Aledo ME, Medina-Mirapeix F, Escolar-Reina P, MontillaHerrador J, Collins SM. Relevant patient perceptions and experiences for evaluating quality of interaction with physiotherapists during outpatient rehabilitation: a qualitative study. Physiotherapy 2014;100:73-9.

[30] Nijs J, Paul van Wilgen C, Van Oosterwijck J, van Ittersum M, Meeus M. How to explain central sensitization to patients with 'unexplained' chronic musculoskeletal pain: practice guidelines. Man Ther 2011;16:413-8.

[31] Beurskens AJ, de Vet HC, Koke AJ, Lindeman E, van der Heijden GJ, Regtop W, et al. A patient-specific approach for measuring functional status in low back pain. J Manipulative Physiol Ther 1999;22:144-8.

[32] Lindstrom I, Ohlund C, Eek C, Wallin L, Peterson LE, Fordyce WE, et al. The effect of graded activity on patients with subacute low back pain: a randomized prospective clinical study with an operant-conditioning behavioral approach. Phys Ther 1992;72:279-90, discussion 91-3.

[33] Shaw WS, Campbell P, Nelson CC, Main CJ, Linton SJ. Effects of workplace, family and cultural influences on low back pain: what opportunities exist to address social factors in general consultations? Best Pract Res Clin Rheumatol 2013;27:637-48.

[34] Smeets RJ, Vlaeyen JW, Kester AD, Knottnerus JA. Reduction of pain catastrophizing mediates the outcome of both physical and cognitivebehavioral treatment in chronic low back pain. J Pain 2006;7:261-71.

[35] Wertli MM, Burgstaller JM, Weiser S, Steurer J, Kofmehl R, Helc U. Influence of catastrophizing on treatment outcome in patients with nonspecific low back pain: a systematic review. Spine 2014;39:263-73

[36] Thomas JS, France CR. Pain-related fear is associated with avoidance of spinal motion during recovery from low back pain. Spine 2007;32:E460-6.

[37] Leeuw M, Goossens ME, van Breukelen GJ, Boersma K, Vlaeyen JW. Measuring perceived harmfulness of physical activities in patients with chronic low back pain: the Photograph Series of Daily Activities - short electronic version. J Pain 2007;8:840-9.

[38] Ihlebaek C, Eriksen HR. The 'myths' of low back pain: status quo in Norwegian general practitioners and physiotherapists. Spine 2004;29:1818-22.

[39] Vlaeyen JW, de Jong J, Geilen M, Heuts PH, van Breukelen G. Graded exposure in vivo in the treatment of pain-related fear: a replicated singlecase experimental design in four patients with chronic low back pain. Behav Res Ther 2001;39:151-66.

[40] Vlaeyen JW, de Jong J, Geilen M, Heuts PH, van Breukelen G. The treatment of fear of movement/(re)injury in chronic low back pain: further evidence on the effectiveness of exposure in vivo. Clin J Pain 2002;18:251-61.

Available online at www.sciencedirect.com 